\title{
Primary Malignant Musculosqueletal Tumors of Members in Adult in Togo
}

\author{
Atchi Walla1 ${ }^{*}$, Faré Gnandi-Pio², Piriziwè Dossim¹, Gamal Ayouba3 ${ }^{3}$, Tchaa Towoezim¹, \\ Tchin Darre', Anani Abalo' ${ }^{4}$, Michel Dossim ${ }^{1}$ \\ ${ }^{1}$ Service de Chirurgie Orthopédique et Traumatologique, CHU SylvanusOlympio, Lomé, Togo \\ ${ }^{2}$ Service de Chirurgie Orthopédique et Traumatologique, CHU Kara, Kara, Togo \\ ${ }^{3}$ Service de Chirurgie Générale du CHP de Kpalimé, Kpalimé, Togo \\ ${ }^{4}$ Laboratoire d'Anatomie et Cytologie Pathologiques, CHU SylvanusOlympio, Lomé, Togo \\ Email: "atchi.walla@yahoo.fr
}

Received 13 March 2016; accepted 23 April 2016; published 26 April 2016

Copyright (C) 2016 by authors and Scientific Research Publishing Inc.

This work is licensed under the Creative Commons Attribution International License (CC BY). http://creativecommons.org/licenses/by/4.0/

(c) (i) Open Access

\section{Abstract}

Purpose: Primary malignant musculosqueletal tumors in adult are rare affections group and its treatment is still a real challenge today. The aim of this work was to describe the epidemiologic and treatment aspects of these tumors in the national reference center of our country. Materiel and Methods: It was a retrospective review of primary malignant musculosqueletal tumors treated in orthopedics and trauma unit of Sylvanus Olympio teaching hospital of Lomé, Togo from January 2000 to December 2014. Results: During the study period, 28 cases were selected and reviewed. There were 17 men $(60.71 \%)$ and 11 women (39.29\%). The average age was 32.7 years. There were 20 cases (71\%) of primary malignant bone tumors (PMBT) and 8 cases (29\%) of primary malignant soft tissues tumors (PMSTT). There were 6 (30\%) of osteosarcoma. The tumor was located in the bones of the forearm and wrist/hand in $2(10 \%)$ patients for each anatomical site; for the lower limb, around knee in 7 (35\%) patients. Eight patients had PMSTT (28, 57\%). There were three cases of rhabdomyosarcoma, 2 cases of fibrosarcoma. Tumors were located around knee in 4 cases and around ankle/foot in 3 cases. In the two groups of tumor, tumor resection was performed in 5 patients $(17.86 \%)$ and limb amputation indicated in 23 patients $(82.14 \%)$, was performed in 15 (53.57\%) and 8 patients (37.78\%), rejected it and left hospital against medical advice. Conclusion: Malignant musculoskeletal tumors are relatively rare in Togo. Their treatment is based on radical surgery which is often not supervised by adjuvant therapies. Ignorance, poverty of the population and embryonic state of diagnostic and treatment infrastructures are the obstacles to their care. Education and awareness must be integrated to care and fight against this group of diseases.

\section{Keywords}

Primary Bone Tumors, Soft Tissue Tumors, Osteosarcoma, Rhabdomyosarcoma, Togo

\footnotetext{
"Corresponding author.
}

How to cite this paper: Walla, A., Gnandi-Pio, F., Dossim, P., Ayouba, G., Towoezim, T., Darre, T., Abalo, A. and Dossim, M. (2016) Primary Malignant Musculosqueletal Tumors of Members in Adult in Togo. Open Journal of Orthopedics, 6, 103-107. http://dx.doi.org/10.4236/ojo.2016.64015 


\section{Introduction}

Musculoskeletal tumors are relatively rare and are very variably distributed worldwide [1]. Among them, malignant varieties are rare but can be more aggressive with a high potential for systemic spread [2]. The incidence of malignant primary bone tumors (PMBT) is around 9 per million inhabitants per year [3]. They are burdened with high mortality rates.

These malignancies thus form a complex and difficult group of diseases whose diagnosis, treatment, monitoring and prognosis remain a challenge despite various existing therapeutic modalities [4] [5].

This challenge is especially huge in developing countries, where patients often consult at a very advanced stage in an environment where poverty, ignorance and embryonic state of infrastructures of care coexist. It was notified by publications from sub-Saharan Africa [6] [7].

The aim of this study was to describe the epidemiological profile and aspects of management of these tumors in the national reference center of our country.

\section{Patients and Methods}

It was a retrospective study that included patients at least 15 years, diagnosed and treated for primary malignant musculosqueletal tumors from January 2000 to December 2014 in the Orthopedic and Trauma Surgery unit of Lomé Sylvanus Olympio teaching hospital. The diagnosis was evoked on the basis of the clinical findings. $\mathrm{X}$-ray and scan sometimes have confirmed the diagnosis. Biopsy brought confirmation. Were collected and analyzed data on age, gender, anatomical site, histopathological type, and therapeutic methods of these tumors and their outcomes. These data were manually collected survey forms from hospitalization and operating room registers. Data were recorded using Epi Info software version 3.5.1.

\section{Ethical Aspects}

This study was authorized and conducted under the direction of the chief of orthopedic trauma unit of Sylvanus Olympio teaching hospital. The confidentiality of information collected has been preserved.

\section{Results}

About 15 years, 71 patients were diagnosed as primitive malignant musculoskeletal tumors in the service. There were $36(50.7 \%)$ patients with PMBT and 35 (49.3\%) patients with PMSTT. Forty three patients records were not selected for the study because 18 left hospital against medical advice and 25 was not include because of lack of all necessary information for the study.

The work involved a total of 28 patients including 17 men and 11 women. The average age was 32.7 years. There were 20 cases (71\%) of PMBT and 8 cases (29\%) of PMSTT.

\subsection{Primary Malignant Bone Tumors (PMBT)}

Primary bone tumors were seen in 20 cases $(71.43 \%)$; 12 cases $(60 \%)$ in males and 8 cases $(40 \%)$ in females. Mean age of patients with primary bone tumors was 30.5 years.

There were 6 patients $(30 \%)$ of osteosarcoma, $3(15 \%)$ of chondrosarcoma, $3(15 \%)$ of Ewing's sarcoma, 3 (15\%) of myeloma and $3(15 \%)$ of lymphoma (Table 1$)$.

The tumor was located in the bones of the for arm and wrist/hand in $2(10 \%)$ patients for each anatomical site; for the lower limb, around knee in $7(35 \%)$ patients, femur in $2(10 \%)$ patients and tibia/fibula in $2(10 \%)$ patients was affected (Table 2).

\subsection{Primary Malignant Soft Tissue Tumors (PMSTT)}

Of the eight patients with primary malignant soft tissue tumors (28.57\%), five (5) was males. It was three cases of rhabdomyosarcoma, 2 cases of fibrosarcoma, one case for each other of schwannoma, angiosarcoma and leiomyosarcoma. The malignant soft tissue tumors were located around knee in 4 cases and around ankle/foot in 3 cases.

\subsection{Treatment and Outcome of Musculosqueletal Malignant Tumors}

In the group of PMBT, of the 20 cases, conservative surgery was done in 3 patients. For the other 17 patients, 
Table 1. Malignant primary bone tumors distribution.

\begin{tabular}{ccc}
\hline & Number & $\%$ \\
\hline Osteosarcoma & 6 & 30 \\
Chondrosarcoma & 3 & 15 \\
Ewing's sarcoma & 3 & 15 \\
Myeloma & 3 & 15 \\
Lymphoma & 3 & 15 \\
Chordoma & 2 & 10 \\
Total & 20 & 100 \\
\hline
\end{tabular}

Table 2. Anatomical localizations of primary bone tumors.

\begin{tabular}{ccc}
\hline & Number & $\%$ \\
\hline Around the shoulder & 1 & 5 \\
Humerus & 1 & 5 \\
Around the elbow & 1 & 5 \\
Radius/ulna & 2 & 10 \\
Wrist/hand & 2 & 10 \\
Pelvis and hip & 1 & 5 \\
Femur & 2 & 10 \\
Around the knee & 7 & 35 \\
Tibia/fibula & 2 & 10 \\
Ankle/foot & 1 & 5 \\
Total & 20 & 100
\end{tabular}

amputation was indicated. Six patients had refused amputation and left hospital against medical advice. Among the 11 patients amputated, two had been able to pay adjuvant chemotherapy, four were fitted. Two patients died in an average of five months while the others were lost to view.

In PMSTT group, excision was performed in two patients including one death in intra operative (large thigh buttock rhabdomyosarcoma with blood loss). The second patient relapsed at 7 months and was treated with amputation. In the other six patients with PMSTT, 4 were amputated while two rejected amputation and left for traditional treatment. On these four amputations, 2 were reviewed with recurrence and spread of cancer disease and died.

Of the 28 cases included in the study, tumor resection was performed in 5 patients $(17.86 \%)$ and limb amputation indicated in 23 patients $(82.14 \%)$ was performed in $15(53.57 \%)$ and 8 patients $(37.78 \%)$, rejected it and left hospital against medical advice. Ultimately, among patients who adhered to treatment and follow-up regularly, five (18\%) died in our service.

\section{Discussion}

Epidemiologically, we noted in the group of primary bone tumors, the balance of osteosarcoma followed by chondrosarcoma and Ewing's sarcoma. This result confirms the tendency of studies on these tumors in Togo [8]-[10]. Regarding the primary soft tissue tumors, fibrosarcoma and rhabdomyosarcoma were seen in majority.

This distribution seems more random us especially at the national level, our service is not alone, in care of soft tissue tumors; general surgery services are also involved. In this group of tumors, Dabak N. highlighted regional differences in their distribution [4].

Surgical options for treatment of extremity musculoskeletal tumors include amputation and wide surgical excision [11]-[13]. But now, in more cases, limb salvage surgery has replaced amputation for malignant musculoskeletal tumors [14] because of early diagnosis and prosthesis using after resection. In addition, embryonic state of adequate care infrastructures does not allow reconstruction surgery after resection which remains a challenge even in developed countries [15].

In our study, we did amputation in the majority in $82.14 \%$ of cases because patients were received at a late stage with large tumors; and chemotherapy/radiation therapy have often not been initiated or because of their unavailability or either because of their cost considerably above the patient means. Eyesan SU [5] reported the same reasons in its study. 
One feature in this study was the proportion of patients who had rejected amputation (37.78\%) preferring to leave against medical advice or to confide to traditional healers. This fact is a sociological reality that indicates that beliefs are still strong in our communities. Through ignorance, people continue to assimilate a tumor to a curse or a bad spell cast by one third to the patient. Thus, the treatment of such diseases must incorporate this sociological aspect through education and awareness of populations.

Our work, in the center of national reference, is the first study in the country that was interested in primitive malignant musculoskeletal tumors in adults. It shows limits of retrospective review. The absence of MRI and scintigraphy was disability in lesion assessment and therapeutic approach [16]. In addition, the unique pathology laboratory of our country which is in our center has no technical means to perform immunohistochemistry in order to establish a classification in accordance with WHO [17].

Nevertheless, this work reflects the difficulties that practitioners in developing countries like ours may face in the recognition and treatment planning of this complex group of tumors.

\section{Conclusion}

Malignant musculoskeletal tumors are relatively rare in Togo. Their treatment is based on radical surgery which is often not supervised by adjuvant therapies. Ignorance, poverty of the population and embryonic state of diagnostic and treatment infrastructures are the obstacles of their care. Education and awareness must be integrated to care and fight against this group of diseases.

\section{References}

[1] Bergovec, M., Kubat, O., Smerdelj, M., Seiwerth, S., Bonevski, A. and Orlic, D. (2015) Epidemiology of Musculoskeletal Tumors in a National Referral Orthopedic Department. A Study of 3482 Cases. Cancer Epidemiology, 18 February, pii: S1877-7821(15)00035-1.

[2] Schwab, J.H., Lozano-Calderon, S.A., Mankin, H.J., Raskin, K.A. and Hornicek, F.J. (2014) What's New in Primary Bone Tumors. Journal of Bone \& Joint Surgery, 96, 2099-2104.

[3] Solooki, S., Vosoughi, A.R. and Masoomi, V. (2011) Epidemiology of Musculoskeletal Tumors in Shiraz, South of Iran. Indian Journal of Medical and Paediatric Oncology, 32, 187-191.

[4] Dabak, N., Cirakl, A., Gülman, B., Selçuk, M.B. and Bariş, S. (2014) Distribution and Evaluation of Bone and Soft Tissue Tumors in the Middle Black Sea Region. Acta Orthopaedica et Traumatologica Turcica, 48, 17-24. http://dx.doi.org/10.3944/AOTT.2014.3013

[5] Eyesan, S.U., Obalum, D.C., Nnodu, O.E., Abdulkareem, F.B. and Ladejobi, A.O. (2009) Challenges in the Diagnosis and Management of Musculoskeletal Tumours in Nigeria. International Orthopaedics, 33, 211-213.

[6] Eyesan, S.U., Obalum, D.C., Onovo, D.O., Ketiku, K.K. and Abdulkareem, F.B. (2009) Indications for Ablative Surgery in Extremity Musculoskeletal Tumours. Nigerian Quarterly Journal of Hospital Medicine, 19, 206-209.

[7] Kouame, M., Yepie, A., Traore, M., Anoumou, M., Gogoua, R., Kone, B. and Varango, G. (2015) Tumeurs osseuses des membres: Les écueils de la prise en charge dans notre contexte. Livre des résumé $11^{\text {ème }}$ congrès de la Société Africaine d'Orthopédie (SAFO), p 52.

[8] Walla, A., James, Y.E., Amakoutou, K., Abalo, A., Dossim, A.M., Gnandi-Pio, F. and Ayouba, G. (2015) Les tumeurs osseuses primitives des membres au CHU Tokoin de Lomé. European Scientific Journal, 11, 149-157.

[9] Darré, T., Amégbor, T., Blitti, C.M., Saka, B., Mouhari-Touré, A., Sonhaye, L., Bissa, H., Pegdessou, E., Sewa, E. and Napo-Koura, G. (2013) Profil histo-épidémiologique des sarcomes des tissus mous au Togo. Carcinologie Clinique en Afrique, 12, 11-15.

[10] Koffi, A., Tchin, D., Lantam, S., Faré, G.P. and Napo-Koura, G. (2009) Aspects épidémiologiques et histopathologiques de 178 cas de cancers primitifs observés au CHU de Lomé. Revue Africaine de Pathologie, 8, 3-7.

[11] Abbas, J.S., Holyoke, E.D., Moore, R. and Karakousis, L.P. (1981) The Surgical Treatment and Outcome of Soft Tissue Sarcoma. Archives of Surgery, 116, 765. http://dx.doi.org/10.1001/archsurg.1981.01380180025006

[12] Grimer, R.J., Carter, S.R., Tillman, R.M., et al. (1999) Endoprosthetic Replacement of the Proximal Tibia. Journal of Bone and Joint Surgery, 81, 488-494. http://dx.doi.org/10.1302/0301-620X.81B3.9234

[13] Shalaby, S., Shalaby, H. and Bassiony, A. (2006) Limb Salvage for Osteosarcoma of the Distal Tibia with Resection Arthrodesis, Autogenous Fibular Graft and Ilizarov External Fixator. Journal of Bone and Joint Surgery, 88, 16421646. http://dx.doi.org/10.1302/0301-620X.88B12.17879

[14] Ogura, K., Miyamoto, S., Sakuraba, M., Fujiwara, T., Chuman, H. and Kawai, A. (2015) Intercalary Reconstruction 
after Wide Resection of Malignant Bone Tumors of the Lower Extremity Using a Composite Graft with a Devitalized Autograft and a Vascularized Fibula. Sarcoma, 2015, Article ID: 861575. http://dx.doi.org/10.1155/2015/861575

[15] Schwab, J.H., Springfield, D.S., Raskin, K.A., Mankin, H.J. and Hornicek, F.J. (2013) What's New in Primary Malignant Musculoskeletal Tumors. Journal of Bone and Joint Surgery, 18, 2240-2246.

[16] Chan, W.P. (2013) Magnetic Resonance Imaging of Soft-Tissue Tumors of the Extremities: A Practical Approach. World Journal of Radiology, 28, 455-459.

[17] Fletcher, C.D., Unni, K.K., Mertens, F., et al. (2002) WHO Classification of Tumors: Pathology and Genetics in Tumors of Soft Tissue and Bone. IARC Press, Lyon. 